九州大学学術情報リポジトリ

Kyushu University Institutional Repository

\title{
Wind Lens Performance Investigation at Low Wind Speed
}

M. M. Takeyelde in

School of Mechanical Engineering, Faculty of Engineering, Universiti Teknologi Malaysia

Tholudin Mat Lazim

School of Mechanical Engineering, Faculty of Engineering, Universiti Teknologi Malaysia

Iskandar Shah Ishak

School of Mechanical Engineering, Faculty of Engineering, Universiti Teknologi Malaysia

Nik Mohd, N. A.R

School of Mechanical Engineering, Faculty of Engineering, Universiti Teknologi Malaysia

他

https://doi.org/10.5109/4150467

出版情報：Evergreen. 7 (4)，pp.481-488，2020-12. 九州大学グリーンテクノロジー研究教育センター バージョン：

権利関係 : 


\title{
Wind Lens Performance Investigation at Low Wind Speed
}

\author{
M. M. Takeyeldein ${ }^{1, *}$, Tholudin Mat Lazim ${ }^{1}$, Iskandar Shah Ishak ${ }^{1}$, \\ Nik Mohd, N.A.R ${ }^{1}$, and Essam Abubakr Ali ${ }^{1}$ \\ ${ }^{1}$ School of Mechanical Engineering, Faculty of Engineering, Universiti Teknologi Malaysia, Malaysia
}

*Author to whom correspondence should be addressed,

E-mail: mtemohamed2@live.utm.my

(Received June 4, 2020; Revised November 16, 2020; accepted November 16, 2020).

\begin{abstract}
In this research work, we investigated a diffuser augmented wind turbine's performance or better known as a wind lens. The wind lens consists of a circular flanged diffuser and a horizontal axis wind turbine with a diameter of $0.6 \mathrm{~m}$. The diffuser length to the diameter ratio is 0.226 , and the flange height to diameter ratio is 0.1 . The performance of the wind Lens is investigated numerically by solving the flow field using Reynolds Averaged Navier-Stokes for incompressible flow. The finding of this work shows that the flange's role is significant to the performance; also, it shows that the opening angle of the diffuser is essential if the rotation speed of the turbine is set wisely. The wind lens's output torque at an inlet speed of $5 \mathrm{~m} / \mathrm{s}$ is superior to the bare turbine by $30-60 \%$, which shows the wind lens's usefulness at low wind speed.
\end{abstract}

Keywords: Wind lens, Wind turbine aerodynamics, Flanged diffuser, DAWT.

\section{Introduction}

Wind energy is currently is one of the cheapest ways to add new power generating capacity in many countries. The production capacity of wind energy has increased more than 30 times in the last two decades. Many Countries had achieved producing $20 \%$ of their electricity from wind energy in 2018, such as Denmark, Ireland, Uruguay, and Portugal. 1,2 .

The world produced $591 \mathrm{GW}$ of electricity from Wind Energy by the end of 2018, representing 5.5\% of the world's electricity production and $50 \%$ of the renewable energy production if hydropower is excluded. Figure 1 shows the share of Renewable Energy in the world's electricity production. The top three countries, China, the USA, and Germany produced approximately $60 \%$ of the world's production from wind energy ${ }^{2)}$.

Wind power is directly proportional to the cube of the wind speed ${ }^{3)}$, and countries with average low wind speed such as Malaysia might not find it worthy of producing energy from wind ${ }^{4-6)}$.

A diffuser duct placed in a free flow has been proved to accelerate the airflow at its inlet ${ }^{7,8}$. Many researchers have proved that mating a turbine with a diffuser increases the power significantly to exceed the Betz limit, which is $59.3 \%{ }^{9,10)}$; wind turbines shrouded with a diffuser are known as diffuser augmented wind turbine (DAWT) or Wind Lens ${ }^{11)}$.

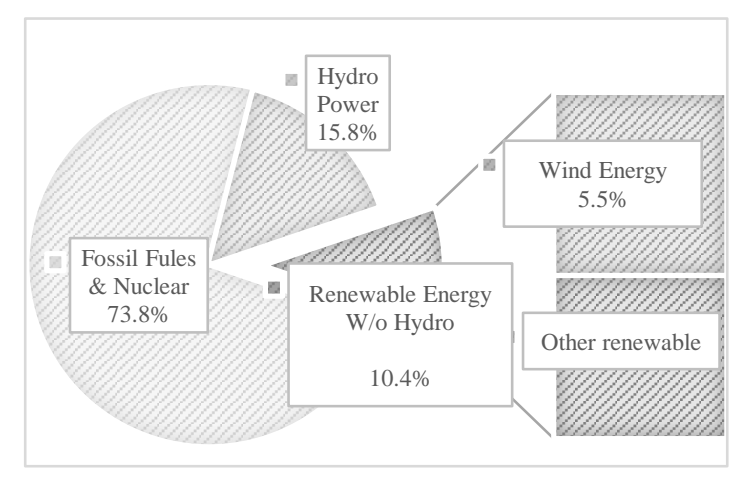

Fig. 1: Global Electricity Production End-2018 2)

For a subsonic flow, two main parameters influence the flow behavior inside a diffuser: Firstly, the area ratio between the exit and the throat, and secondly, the back pressure at the diffuser rear ${ }^{12)}$

DAWT's early designs had a long length diffuser with a large opening angle to make sure the area ratio between the diffuser inlet and output is high. However, the large opening angle causes adverse pressure gradient inside the diffuser walls and hence flow separation, which urged the need of using boundary layer control methods such as air slots or multistage diffusers, which added complexity to their designs. ${ }^{13-16)}$.

\subsection{Difference between DAWT and Wind lens}

The early designs of DAWT have never been upgraded 
to become a commercial product due to the complexity added by the boundary layer controllers and the cost added by the long diffuser. To solve this problem, a group of researchers at Kyushu University had introduced the concept of Wind lens ${ }^{8,11,17,18)}$.

Wind lens is a compact ducted wind turbine characterized by the following: it has a small length to diameter ratio of less than 0.4 , and it has a high vertical flange at its rear. The flange holds an essential role in the wind lens concept because it acts as a vortex generator, which produces a low-pressure zone at the back of the wind-lens, which finally helps the flow accelerate ${ }^{11,18)}$.

The wind lens: unlike the traditional early designs of DAWT, does not rely on increasing the area ratio between the inlet and output diameter; however, it depends on reducing the backpressure by the mean of the flange.

Wind-lens designs have been proven practical and efficient; it might increase the turbine torque by $100 \%$ as reported by Ohya et al. ${ }^{11,18)}$ but with the price of a total drag increase. Many other researchers have further investigated the concept of the wind lens or flanged diffuser ${ }^{19-22)}$.

Wind lens has some advantages over bare turbines such as having fewer wake noises, better performance with yaw direction, in addition to being more friendly to birds, and safer in case of blade fractures; however, the main advantage of wind lens over bare turbines is that wind lens accelerates the axial velocity which allows the turbine rotor to have low start-up speed and cut-in speed ${ }^{9)}$, while keeping good efficiency which might allow building wind farms in areas with a lower average speed such as Malaysia; few prototypes are already built at locations in Japan and China ${ }^{18)}$.

In this research, we have applied the wind lens concept to a rotor that was explicitly designed for low wind speeds and investigated its performance at wind speed $5 \mathrm{~m} / \mathrm{s}$ at various opening angles.

\section{Model description}

The wind lens systems consist of two main parts; the first part is a 3-bladed horizontal axis wind turbine (HAWT), and the second part is a cylindrical diffuser that surrounds the turbine. The description of the two parts is described in the following subsection.

\subsection{Bare turbine description:}

The turbine is a 3-blade horizontal axis wind turbine with a diameter of $0.6 \mathrm{~m}$, and twist and chord distribution shown in Table1. The blade's cross-section is the thin airfoil SD2030, which is a suitable choice for low Reynolds flow applications, as illustrated in ${ }^{23)}$. The turbine blade is shown in Figure 2.
Table 1 Geometrical Description of the Bare Turbine

\begin{tabular}{|c|c|c|}
\hline Position $(\mathrm{m})$ & Chord $(\mathrm{m})$ & Twist $\left(^{\circ}\right)$ \\
\hline 0.06 & 0.09 & 20 \\
\hline 0.09 & 0.0825 & 12.2 \\
\hline 0.12 & 0.075 & 8 \\
\hline 0.15 & 0.0675 & 5.3 \\
\hline 0.18 & 0.06 & 3.6 \\
\hline 0.21 & 0.0525 & 2.3 \\
\hline 0.24 & 0.045 & 1.3 \\
\hline 0.27 & 0.0375 & 0.6 \\
\hline 0.3 & 0.03 & 0 \\
\hline
\end{tabular}



Fig. 2: Wind Turbine Blade

\subsection{Diffuser description}

The diffuser configuration to be studied here follows the same concept adopted by Ohya et al. ${ }^{18)}$, a diffuser with a short length and extended flange height $\mathrm{L} / \mathrm{D}$, as shown in Figure 3; the diffuser's dimensions are listed in Table 2.

Table 2 Diffuser Geometrical Description

\begin{tabular}{|c|c|}
\hline Inlet diameter (D) & $0.6 \mathrm{~m}$ \\
\hline Diffuser length (L)/D & 0.2 \\
\hline Flange height (H)/D & 0.1 \\
\hline Opening angle & $7,10,20$, and $30^{\circ}$ \\
\hline
\end{tabular}



a) A Schematic Diagram of the Wind lens 


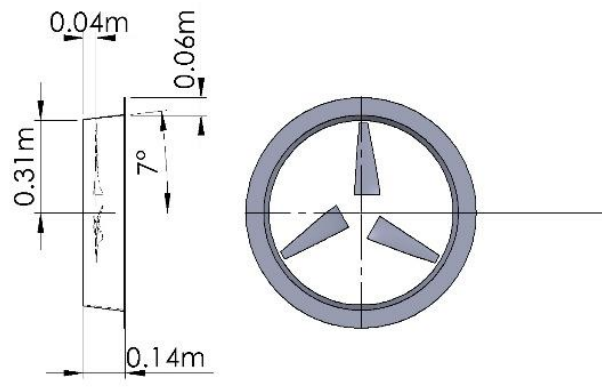

b) A Technical Drawing of the Wind lens

Fig. 3: Description of the Wind lens and its dimensions.

\section{CFD Simulation}

The turbine performance and the wind lens have been investigated using 3D CFD simulation by solving the Reynolds averaged Navier-Stokes equations for incompressible flow, using CFX Ansys software. The continuity and momentum equation resulting from Reynolds averaged Navier-stokes equations are as follows:

$$
\begin{aligned}
& \frac{\partial\left(\bar{u}_{i}\right)}{\partial x_{i}}=0 \\
& \frac{\partial\left(\bar{u}_{i}\right)}{\partial t}+\frac{\partial}{\partial x}\left(\bar{u}_{i} \bar{u}_{j}\right)=-\frac{1}{\rho} \frac{\partial \bar{p}}{\partial x_{i}}+v \frac{\partial^{2} \bar{u}_{i}}{\partial x_{i} \partial x_{j}}+\frac{\partial \tau_{i j}}{\partial x_{j}}
\end{aligned}
$$

\subsection{Computational domain description}

As shown in Figure 4a, the computational domain has been divided into two zones, a rotational domain that includes the turbine blade and a stationary zone that includes the diffuser wall. To capture the flow inside the boundary layer inside the rotational domain, a C-grid zone was created with hexahedral structured mesh elements along the blade span from root to tip as shown in Figure $4 \mathrm{~b}$; the height of the first layer close to the wall surface was chosen small enough to make sure $\mathrm{Y}^{+}$is less than 1 . A zone of dense mesh elements is created around the diffuser to capture the pressure gradient that occurs across it. Figure $4 \mathrm{c}$ shows inflation layers, which were also created around the diffuser walls to capture the boundary layer; a similar way was followed by Halawa et al. ${ }^{24)}$ and Ibrahim et al. ${ }^{25)}$. The mesh elements everywhere else in the domain are unstructured 3D tetrahedral cells, created using Ansys meshing.

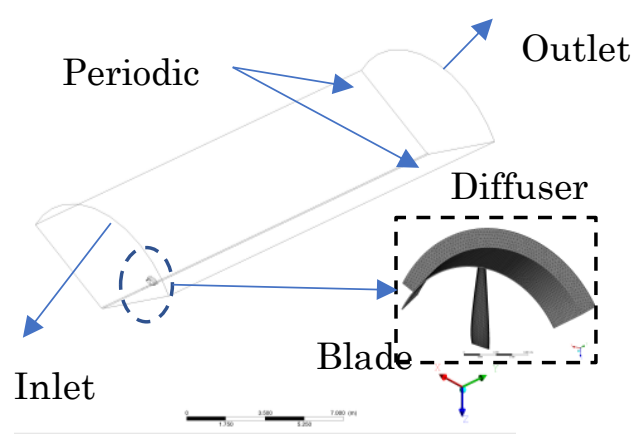

a) Computational Domain and Boundary Conditions

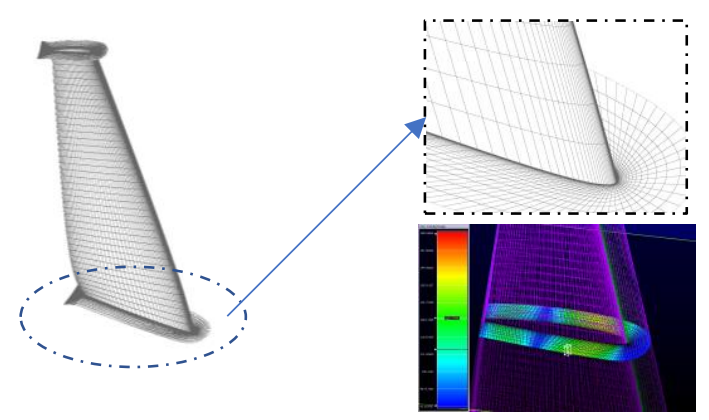

b) C-Grid Around the Blade

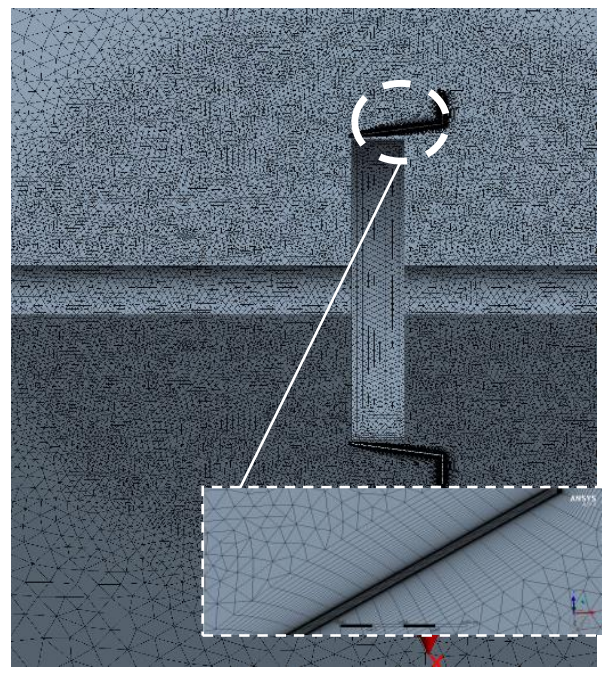

c) Dense Mesh and Inflation Layers around the Diffuser Walls

Fig. 4 Computational Grid for the shrouded turbine

\subsection{Validation of the numerical model}

The validation process was conducted in two steps; the first step is to use CFD to solve the flow around a hollow cylindrical flanged diffuser, which was tested in a wind tunnel by Ohya et al. ${ }^{7)}$. In this experiment, the airspeed at the diffuser's centreline was measured using hot-wire; Figure 5a shows the comparison between CFD results and Experiment results.

The second step is to use CFD to calculate the performance of a scaled version of the NREL phase VI wind turbine, which was tested in a wind tunnel by Cho e 
al 26). The experiment was conducted by fixing the rotational speed at $700 \mathrm{rpm}$ and varying the inlet speed. Figure $5 \mathrm{~b}$ shows the non-dimensional curve of both CFD and Experiment for the same rotor.

Figure 5a \& Figure 5b shows that the CFD model solved by RANS SST turbulent model can reasonably predict the flow around the diffuser walls and the turbine.

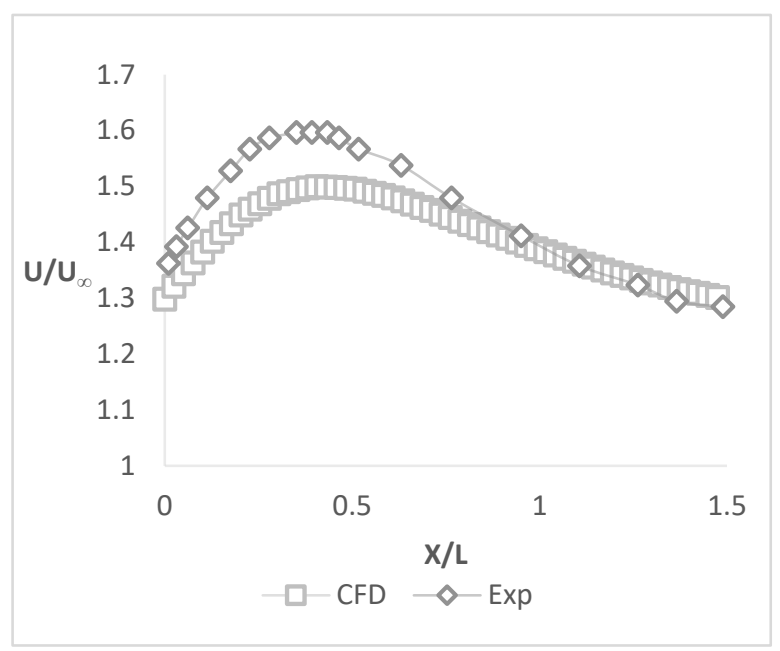

a) The velocity of the flow at the centerline of a hollow diffuser relative to the inlet speed calculated by CFD and wind tunnel testing by Ohya et al. ${ }^{7)}$

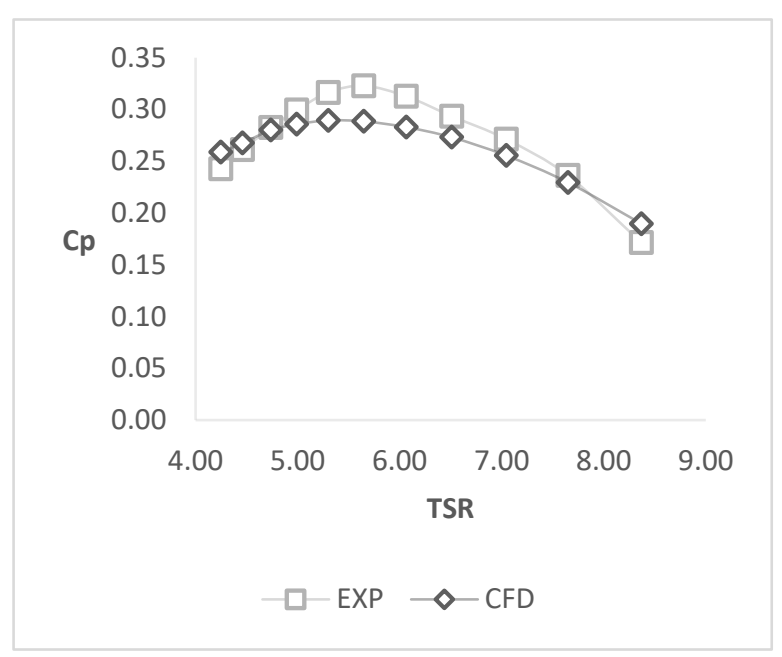

b) Power coefficient of a scaled NREL Phase VI wind turbine calculated by CFD and wind tunnel testing by Cho et al. ${ }^{26)}$.

Fig. 5: Comparison between CFD results and Wind tunnel results from the literature.

\subsection{Grid Sensitivity:}

Grid sensitivity has been carried out by testing the change in the rotor torque at TSR 5.65 by changing the number of elements in the radial direction of the blade, the number of the layers inside the $\mathrm{C}$-grid, the size of the $\mathrm{C}$ grid around the rotor blade, the number of elements in the radial direction of the blade and the length of the rotating domain. As seen in Table 3, the results show that increasing the number of elements more than 200 has a negligible effect on the torque; the change remains less than $0.9 \%$. Increasing the number of layers inside the $\mathrm{C}$ Grid while keeping the C-Grid size constant at $3 \mathrm{~cm}$ shows no significant difference in the torque as well; the changes remain below $0.9 \%$, however, doubling the size of the $\mathrm{C}$ Grid from $3 \mathrm{~cm}$ to $6 \mathrm{~cm}$ while keeping the number of layers constant as 70 increases the torque by $1.35 \%$; further increase in the C-Grid size shows an insignificant change. Similarly, by testing the torque value's sensitivity to the rotating domain length, it is found, as shown in Table 3, that increasing the rotating domain size from $26 \mathrm{~cm}$ to 40 $\mathrm{cm}$ improves the solution by $10 \%$; however, a further increase shows an insignificant change.

Table 3 Torque value of the scaled NREL rotor at TSR 5.65 results from different mesh settings.

\begin{tabular}{|c|c|c|c|c|}
\hline $\begin{array}{c}\text { C-grid } \\
\text { layers }\end{array}$ & $\begin{array}{c}\text { C-Grid } \\
\text { size }\end{array}$ & $\begin{array}{c}\text { Radial } \\
\text { points }\end{array}$ & $\begin{array}{c}\text { Rotating } \\
\text { domain }\end{array}$ & $\begin{array}{c}\text { Torque } \\
\text { (N.m) }\end{array}$ \\
\hline 25 & $3 \mathrm{~cm}$ & 200 & $26 \mathrm{~cm}$ & 14.78 \\
\hline 25 & $3 \mathrm{~cm}$ & 300 & $26 \mathrm{~cm}$ & 14.8 \\
\hline 25 & $3 \mathrm{~cm}$ & 400 & $26 \mathrm{~cm}$ & 14.825 \\
\hline 25 & $3 \mathrm{~cm}$ & 500 & $26 \mathrm{~cm}$ & 14.815 \\
\hline 25 & $3 \mathrm{~cm}$ & 600 & $26 \mathrm{~cm}$ & 14.828 \\
\hline 35 & $3 \mathrm{~cm}$ & 200 & $26 \mathrm{~cm}$ & 14.86 \\
\hline 50 & $3 \mathrm{~cm}$ & 200 & $26 \mathrm{~cm}$ & 14.878 \\
\hline 70 & $3 \mathrm{~cm}$ & 200 & $26 \mathrm{~cm}$ & 14.9 \\
\hline 90 & $3 \mathrm{~cm}$ & 200 & $26 \mathrm{~cm}$ & 14.912 \\
\hline 70 & $6 \mathrm{~cm}$ & 200 & $26 \mathrm{~cm}$ & 14.98 \\
\hline 70 & $9 \mathrm{~cm}$ & 200 & $26 \mathrm{~cm}$ & 15.01 \\
\hline 70 & $12 \mathrm{~cm}$ & 200 & $26 \mathrm{~cm}$ & 15.04 \\
\hline 25 & $3 \mathrm{~cm}$ & 200 & $40 \mathrm{~cm}$ & 16.34 \\
\hline 25 & $3 \mathrm{~cm}$ & 200 & $50 \mathrm{~cm}$ & 16.45 \\
\hline 25 & $3 \mathrm{~cm}$ & 200 & $60 \mathrm{~cm}$ & 16.62 \\
\hline
\end{tabular}

\section{CFD Results and Discussions}

\subsection{Performance of the diffuser alone}

The same numerical model just validated in the previous section is used to solve the new diffuser configuration that was illustrated in section 2.2. Figure 6 shows the flow velocity across the length of the new diffuser configuration. The upstream velocity is accelerated from $5 \mathrm{~m} / \mathrm{s}$ to $6.3 \mathrm{~m} / \mathrm{s}$ inside the diffuser, which means the flow accelerated 1.2 times. A grid independence study was done for the diffuser by changing the height of the first grid layer adjacent to the diffuser wall. 


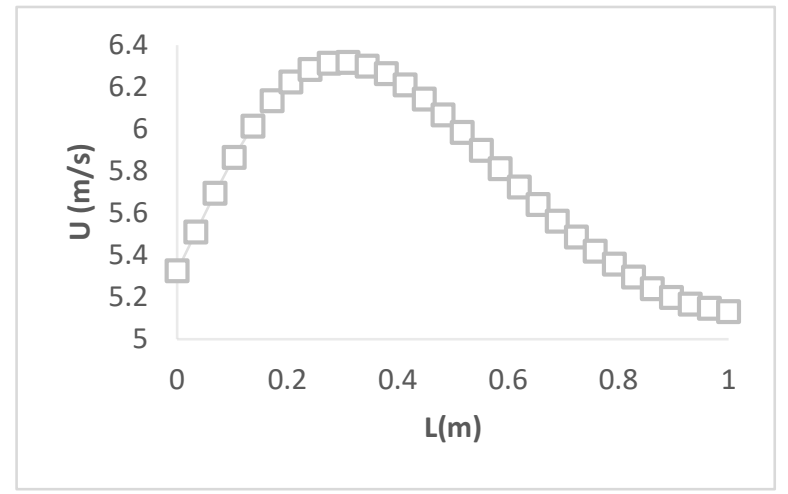

Fig. 6: New Diffuser Configuration Performance

\subsection{Performance of the bare turbine using CFD.}

The bare turbine's performance is also investigated using CFD using a steady-state moving reference frame simulation; the CFD results are then compared with results from Qblade software, which uses blade element momentum theory (BEM) 25) to make sure the CFD results are in the reasonable range. Figure 7 shows the bare turbine performance at an inlet speed of $5 \mathrm{~m} / \mathrm{s}$. The turbine's performance is also tested at different Inlet speeds; as shown in Figure 8, an insignificant increase in the power coefficient occurs at $10 \mathrm{~m} / \mathrm{s}$ inlet speed.

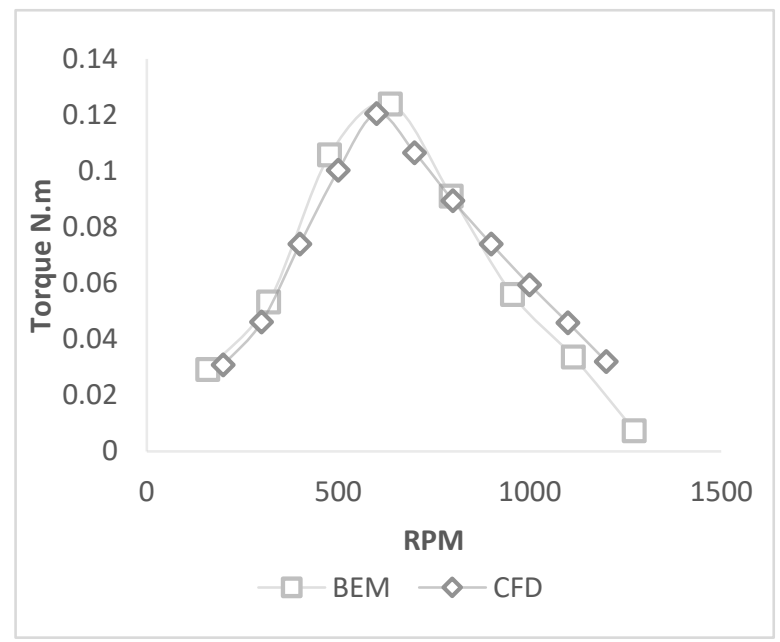

Fig. 7: Bare Turbine Performance at Upstream Speed 5 m/s.

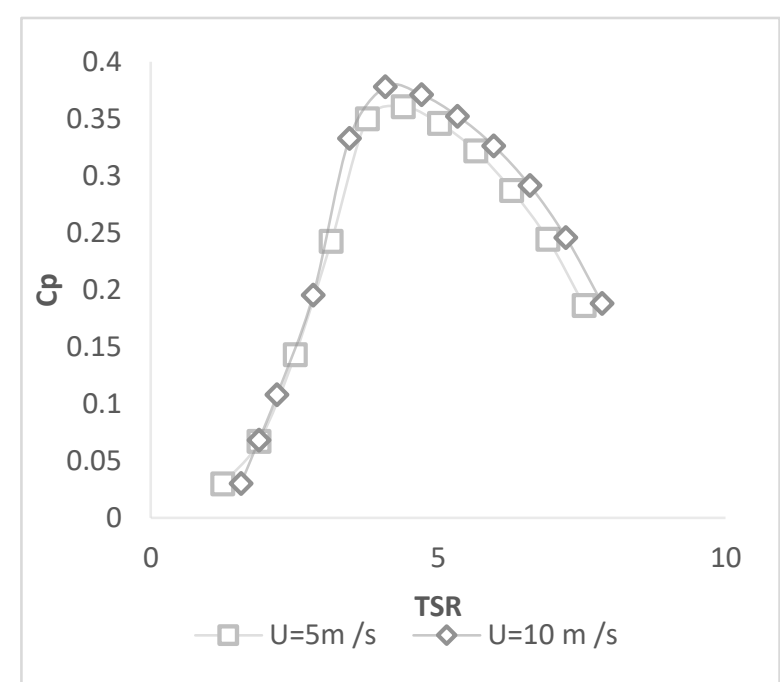

Fig. 8: Bare Turbine Performance at Different Reynolds Number.

\subsection{Performance of the turbine with the diffuser (wind lens)}

This research's main objective is to investigate the wind lens performance, which is illustrated in this section. Figure 9 shows the torque output of the bare turbine and the wind lens; it is demonstrated that the wind lens has a superior performance. The torque increase happens between $4 \%$ up to $107 \%$, which agrees with results from previous research conducted by Ohya et al. ${ }^{18)}$. Ohya et al. reported an increase in power of more than $100 \%$ based on the configuration.

Figure 9 also emphasizes the flange's role because the torque's increase is negligible when the flange is removed from the shroud part.

The wind lens's performance at four different angles $7,10,20$, and $30^{\circ}$ is shown in Figure 10; it is noticed that the turbine torque increases directly with the increase of the opening angle until a certain degree, and then the torque reduces again. However, at high rotational speed as shown in Figure 11; for example, RPM 800, the peak occurs at angle $20^{\circ}$, and then the torque starts to reduce at $30^{\circ}$; at a lower RPM 700, the toque peak occurs at $10^{\circ}$, and at RPM lower than 600, a further increase in the opening angle beyond $7^{\circ}$ does not result in improvement in the performance. 


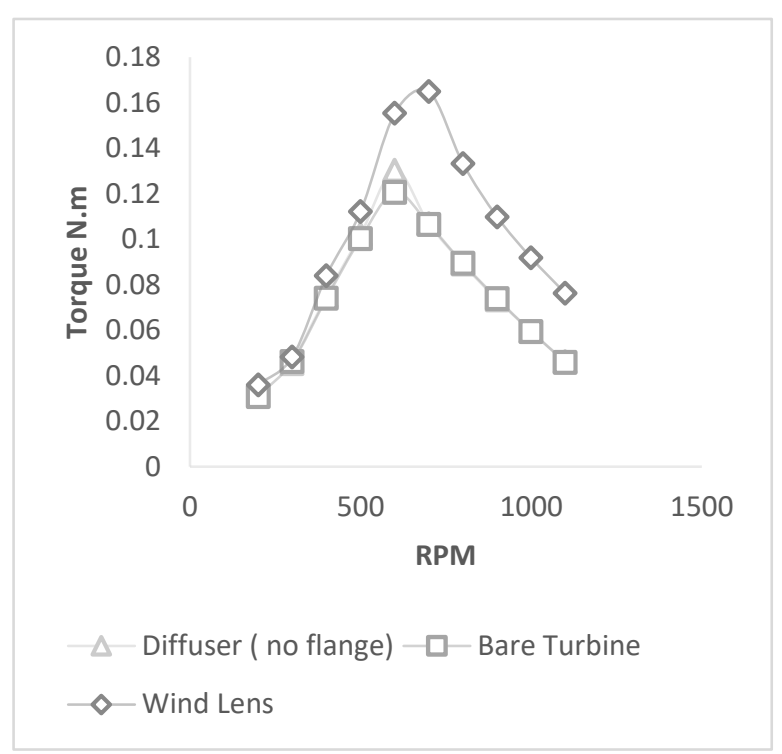

Fig. 9: Bare Turbine Vs. Wind Lens Performance.

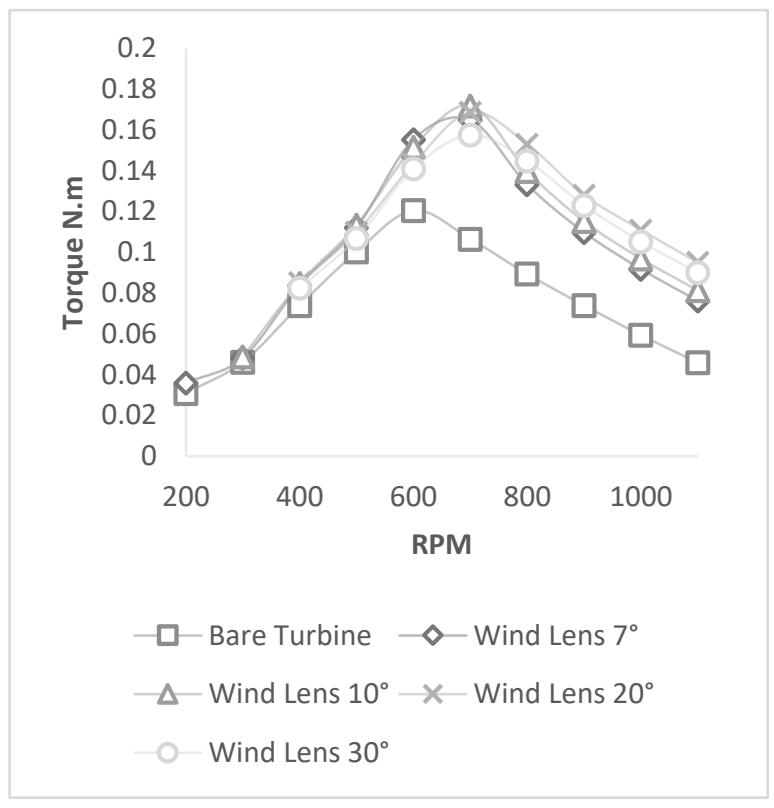

Fig. 10: Wind Lens at Different Opening Angles.

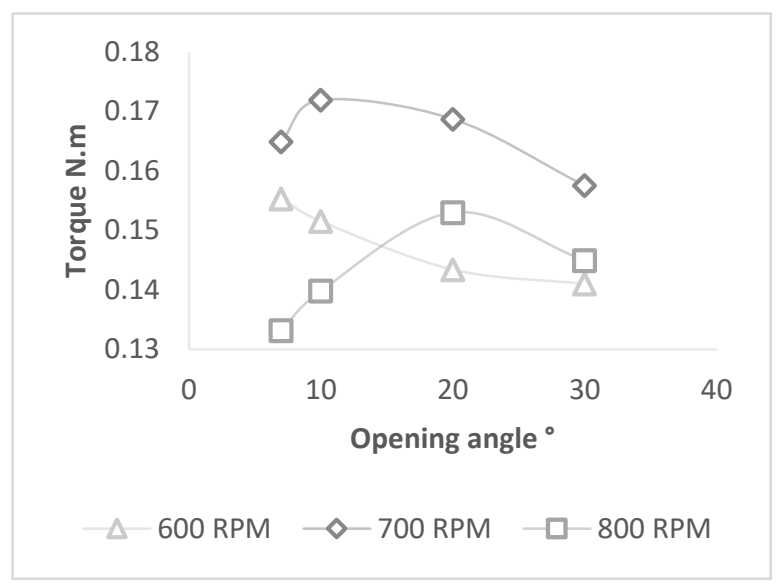

Fig. 11: Torque Sensitivity to the Opening Angle at Different RPM
By taking a cross-sectional plane across the wind lens as shown in Figure 12, it can be noticed through the velocity vectors passing through it that the flow is almost fully attached to the inner walls at an opening angle of $7^{\circ}$ at $600 \mathrm{rpm}$, as shown in Figure 12a.

Figures $12 \mathrm{a}$ and $12 \mathrm{~b}$ show the velocity vector at rotational speed 600 at an opening angle of $7^{\circ}$ and $10^{\circ}$, respectively. The boundary layer has separated at an angle of $10^{\circ}$ while it is still attached to the diffuser walls at $7^{\circ}$ das shown in Figure 12a.

Figure $12 \mathrm{~b}$ and Figure $12 \mathrm{c}$ shows the velocity vector at the same opening angle of $10^{\circ}$. However, at different rotational speeds, 600 and 700, respectively. The boundary layer is separated when the rotational speed is 600 . However, it is reattached again at $\mathrm{rpm} 700$, as shown in Figure $12 \mathrm{c}$.

Figure $12 \mathrm{c}$ and Figure $12 \mathrm{~d}$ show the velocity vectors at rotational speed 700 at an opening angle of $10^{\circ}$ and $20^{\circ}$, respectively. The flow is fully attached to the diffuser walls at an opening angle of $10^{\circ}$. However, it can be shown that at a high opening angle of $20^{\circ}$, the flow has separated from the diffuser walls, and part of the flow has reversed its direction.

The yellow color background in Figure $12 \mathrm{~d}$ represents the area where the flow is still in the upstream direction. The grey spots are the areas where the flow direction is inversed or separated; it can be noticed that the effective shape of the diffuser changed and became narrower.

Figure $12 \mathrm{e}$ and Figure $12 \mathrm{f}$ show the velocity vector at rotational speed 800 at opening angle $20^{\circ}$ and $30^{\circ}$, respectively; it can be seen that the diffuser's effective shape is different in the two cases. The effective diffuser shape in Figure 12f is narrower than in Figure 12e, which means effectively it has a lower opening angle than 20 degrees, and this might explain the loss in toque that occurs. It is shown in Figure 10 that the Wind lens at $30^{\circ}$ has lower performance than the Wind lens at $20^{\circ}$ at rotational speed $800,900,1000$, and 1100 .

It could be concluded that increasing the opening angle increases the torque of the wind lens if the flow is still attached to the diffuser walls, and increasing the rotational speed might help the BL reattach to the diffuser walls for the same opening angle; and finally, the BL separation changes the effective opening angle to the wind lens.



a) $600 \mathrm{RPM} 7^{\circ}$ 


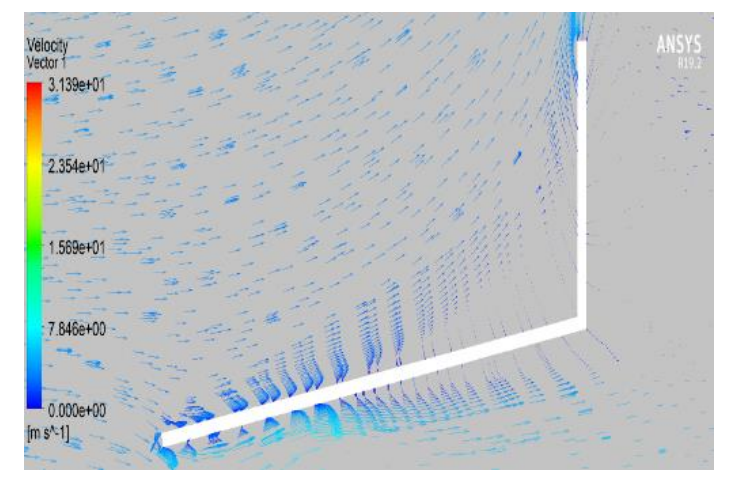

b) $600 \mathrm{RPM} 10^{\circ}$

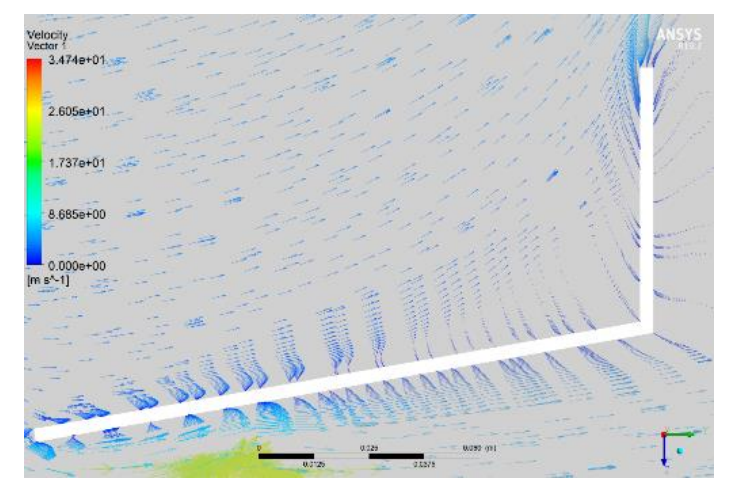

c) $700 \mathrm{RPM} 10^{\circ}$

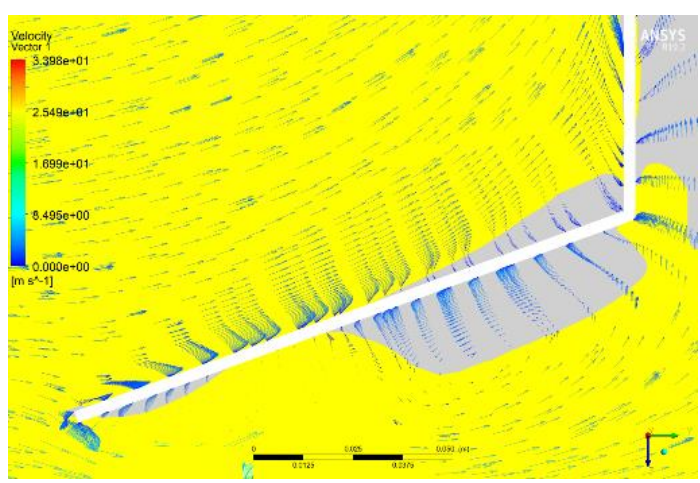

d) $700 \mathrm{RPM} 20^{\circ}$

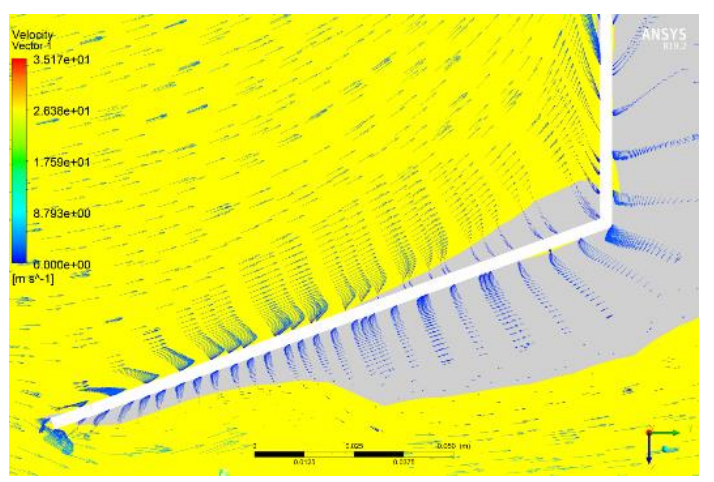

e) $800 \mathrm{RPM} 20^{\circ}$

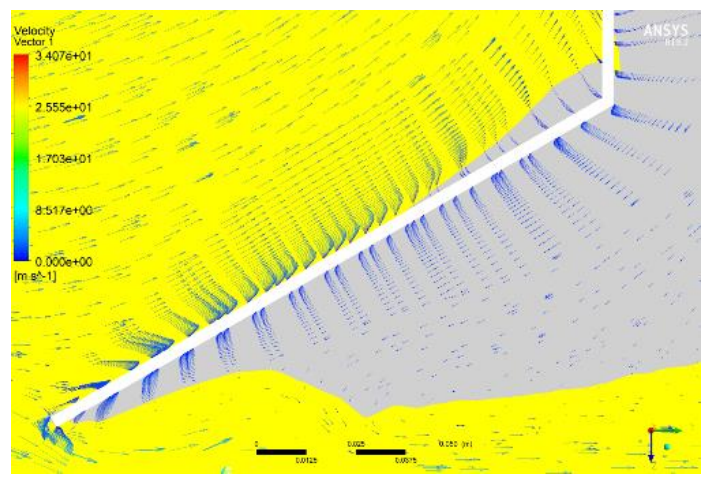

f) $800 \mathrm{RPM} 30^{\circ}$

Fig. 12 Velocity Vector across the Wind Lens at Different RPM and Opening Angles

\section{Conclusion:}

The wind lens system has successfully increased the performance of the turbine by up to $60 \%$. The flange is the most significant element in the wind lens because a diffuser without a flange will have a minimal effect on the performance. The turbine's torque increases directly with the increase of the opening angle if the flow is still attached. The augmentation of the torque is higher at high rotational speeds than it is at lower rotational speeds.

\section{Acknowledgments}

The authors are grateful to the Aeronautical Laboratory of Universiti Teknologi Malaysia for providing valuable technical supports to conduct this research project.

\section{Nomenclature}

$P \quad$ Wind power available

$\rho \quad$ Air Density

$V \quad$ Air Velocity

A Rotor Area

$\bar{u} \quad$ Velocity vector

$x \quad$ Displacement vector

$t$ time

$\bar{p} \quad$ Pressure

$v \quad$ Kinematic viscosity

$\tau_{i j} \quad$ Reynolds stress tensor

Cp Power Coefficient

TSR Tip speed ratio

CFD Computational fluid dynamics

*The overbar indicates a time-averaged quantity. 


\section{References}

1) GWEC, "GLOBAL WIND REPORT 2018," 2019.

2) REN21, "Renewables Global Status Report," 2019.

3) J.F. Manwell, J.G. McGowan, and A.L. Rogers, "Wind energy explained," Wind Energy Explain., vii, 577 p. (2009). doi:10.1002/9781119994367.

4) A. Ali Kadhem, N.I. Abdul Wahab, and A. N. Abdalla, "Wind energy generation assessment at specific sites in a peninsula in malaysia based on reliability indices," Processes, 7 (7) 399 (2019). doi:10.3390/pr7070399.

5) M.R. Islam, R. Saidur, and N.A. Rahim, "Assessment of wind energy potentiality at kudat and labuan, malaysia using weibull distribution function," energy, $36 \quad$ (2) 985-992 (2011). doi:10.1016/j.energy.2010.12.011.

6) A.A. Kadhem, N.I.A. Wahab, I. Aris, J. Jasni, and A.N. Abdalla, "Advanced wind speed prediction model based on a combination of weibull distribution and an artificial neural network," Energies, 10 (11) 117 (2017). doi:10.3390/en10111744.

7) Y. Ohya, T. Karasudani, A. Sakurai, and M. Inoue, "Development of a high-performance wind turbine equipped with a brimmed diffuser shroud," Trans. Jpn. Soc. Aeronaut. Space Sci., 49 (163) 18-24 (2006). doi:10.2322/tjsass.49.18.

8) Y. Klistafani, and M.I. Mukhsen, "Development of a shrouded wind turbine with various diffuser type structures," IOP Conf. Ser. Mater. Sci. Eng., 676 (1) 524-539 (2019). doi:10.1088/1757$899 X / 676 / 1 / 012040$.

9) A. Aranake, V. Lakshminarayan, and K. Duraisamy, "Computational analysis of shrouded wind turbine configurations," 51st AIAA Aerosp. Sci. Meet. Incl. New Horizons Forum Aerosp. Expo., (January) 1-17 (2013). doi:10.2514/6.2013-1211.

10) A.C. Aranake, V.K. Lakshminarayan, and K. Duraisamy, "Computational analysis of shrouded wind turbine configurations using a 3-dimensional rans solver," Renew. Energy, 75 818-832 (2015). doi:10.1016/j.renene.2014.10.049.

11) Y. Ohya, T. Karasudani, T. Nagai, and K. Watanabe, "Wind lens technology and its application to wind and water turbine and beyond," Renew. Energy Environ. Sustain., 22 (2017). doi:10.1051/rees/2016022.

12) J.D. Anderson, "Modern compressible flow with historical perspective.," Boston: McGraw-Hill., 1982. doi:10.1017/S0001924000024027.

13) O. Igra., "Shrouds for aerogenerators," Aiaa J., 14 (10) 1481-1483 (1976). doi:10.2514/3.61486.

14) B.L. Gilbert, R. a. Oman, and K.M. Foreman, "Fluid dynamics of diffuser-augmented wind turbines," $J$. Energy, 2 (6) 368-374 (1978). doi:10.2514/3.47988.

15) P.A. Garc, "Por alejandro garcía montaño," IPENZ Trans., 26 (1/EMCh) 13-19 (1999).

16) D.L.F. Gaden, and E.L. Bibeau, "A numerical investigation into the effect of diffusers on the performance of hydro kinetic turbines using a validated momentum source turbine model," Renew. Energy, $35 \quad$ (6) 1152-1158 (2010). doi:10.1016/j.renene.2009.11.023.

17) K.I. Abe, and Y. Ohya, "An investigation of flow fields around flanged diffusers using cfd," J. Wind Eng. Ind. Aerodyn., 92 (3-4) 315-330 (2004). doi:10.1016/j.jweia.2003.12.003.

18) Y. Ohya, and T. Karasudani, "A shrouded wind turbine generating high output power with wind-lens technology," Energies, 3 (4) 634-649 (2010). doi:10.3390/en3040634.

19) B. Kosasih, and A. Tondelli, "Experimental study of shrouded micro-wind turbine," Procedia Eng., 49 9298 (2012). doi:10.1016/j.proeng.2012.10.116.

20) J. Liu, M. Song, K. Chen, B. Wu, and X. Zhang, "An optimization methodology for wind lens profile using computational fluid dynamics simulation," energy, 109 602-611 (2016). doi:10.1016/j.energy.2016.04.131.

21) M. Lipian, I. Dobrev, M. Karczewski, F. Massouh, and K. Jozwik, "Small wind turbine augmentation: experimental investigations of shrouded- and twinrotor wind turbine systems," energy, 186115855 (2019). doi:10.1016/j.energy.2019.115855.

22) M. Abdelwaly, H. El-Batsh, and M. Bassily Hanna, "Numerical study for the flow field and power augmentation in a horizontal axis wind turbine," Sustain. Energy Technol. Assessments, 31 (December 2018) 245-253 (2019). doi:10.1016/j.seta.2018.12.028.

23) M.M. Takeyeldein, T.M. Lazim, N.A.R.N. Mohd, I.S. Ishak, and E.A. Efkirn, "Wind turbine design using thin airfoil sd2030," Evergreen, 6 (2) 114-123 (2019). doi:10.5109/2321003.

24) A.M. Halawa, B. Elhadidi, and S. Yoshida, "Aerodynamic performance enhancement using active flow control on du96-w-180 wind turbine airfoil," Evergreen, 5 (1) 16-24 (2018).

25) O.M.A.M. Ibrahim, and S. Yoshida, "Experimental and numerical studies of a horizontal axis wind turbine performance over a steep 2d hill," Evergreen, 5 (3) 12-21 (2018).

26) T. Cho, and C. Kim, "Wind tunnel test for the nrel phase vi rotor with $2 \mathrm{~m}$ diameter," Renew. Energy, 65 265-274 (2014). doi:10.1016/j.renene.2013.10.009. 